\title{
An Efficient Protocol for the One Pot Synthesis of Pyranopyrazoles in Aqueous Medium using Triethanolamine as a Catalyst
}

\author{
Jayant P Sonar ${ }^{1}$, Sandeep D Pardeshi ${ }^{1}$, Shrikant A Dokhe ${ }^{1}$, Ashok M Zine ${ }^{2}$, Rajendra P Pawar ${ }^{3 *}$ and Shivaji N Thore $^{3 *}$ \\ ${ }^{1}$ Department of Chemistry, Vinayakarao Patil Mahavidyalaya, Vaijapur-423701, (MS) India \\ ${ }^{2}$ Department of Chemistry, Late Sundarrao Salunke Arts, Science and Commerce College, Majalgaon-431131, (MS) India \\ ${ }^{3}$ Department of Chemistry, Deogiri College, Station Road, Aurangabad-431 005, (MS) India
}

Received: 琒 May 25, 2018; Published: 眥 June 05, 2018

*Corresponding author: Rajendra P Pawar, Shivaji N Thore, Department of Chemistry, Deogiri College, Station Road, Aurangabad- 431 005 (MS) India, Email: snthore@rediffmail.com, rppawar@yahoo.com

\begin{abstract}
Triethanolamine is an efficient and green catalyst for the synthesis of 6-amino-1, 4-dihydro-4-substituted-3-methylpyrano-[2, 3-c] pyrazole-5-carbonitrile in aqueous medium reflux conditions. The procedure is easier, eco friendly, simple with easy workup affording good yield of the corresponding products.
\end{abstract}

Keywords: Multi component reaction; Water media; Pyranopyrazole; Catalyst; Triethanolamine

\section{Introduction}

The present scenario for organic synthesis indicates the crave for green and economical synthesis of organic compounds. One of it is multi component synthesis. Strecker's synthesis for amino acids was the first report on multi component reaction [1]. Last few decades show large development in it. The main aim of such reactions is to fasten the reaction rate by reducing number of steps involved and eventually increase the yield of reaction. In this context to achieve great efficiency catalysts are employed. Catalysts such as Nano $\alpha-\mathrm{Al}_{2} \mathrm{O}_{3}$ supported ammonium dihydrogenphosphate [2], tungstate sulfuric acid [3], $\mathrm{Fe}_{3}-\mathrm{xTixO}_{4} @ \mathrm{SO}_{3} \mathrm{H}$ nanoparticles [4], nano-titania sulfuric acid (15-nm TSA) [5], nanostructured MgO [6], $\mathrm{H}_{14}\left[\mathrm{NAP}_{5} \mathrm{~W}_{30} \mathrm{O}_{110}\right]$ [7] and Zno Nanoparticles [8] were used.

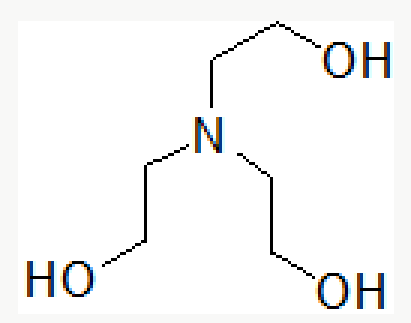

Figure 1.
Organic catalysts such as Triethylamine [9], DABCO [10], Trishydroxymethyl aminomethane [11] are also reported in various organic transformations. Triethanolamine contains basic tertiary amine and primary alcoholic part (Figure 1).

It is used for activation of both $\mathrm{CO}_{2}$ and epoxides to convert them in to cyclic carbonates [12]. It is also reported as a ligand for copper catalyzed hydroxylation of aryl halides in aqueous medium [13]. It is used as aqueous solvent for controllable preparation of $\mathrm{ZnO}$ nano flowers in sol gel technique [14]. Its aqueous solution is reported as electrolyte in $\mathrm{CO}_{2}$ Photo electro-conversion catalyzed by $\mathrm{Cu}$ Doped Graphene-Titania Catalyst [15]. Also it is found to increase the rate of oxidation of mesitylene catalyzed by cobalt bromide [16]. It is used as sacrificial electron donor in photocatalytic system [17]. Furthermore; it improved the catalytic performance of $\mathrm{CuBr} /$ PMDETA in the atom transfer radical polymerization [18]. It is also used as phase transfer catalyst for synthesis of 1-(arylsulfonyl) aryl/heterylmethanes [19]. It is used as medium for synthesis of 3-substituted coumarins using L-proline as a catalyst [20]. It is reported as catalyst in $10 \mathrm{~mol} \%$ for synthesis of 2-amino-3-cyano$4 \mathrm{H}$-pyran derivatives under ultrasound irradiation at $60^{\circ} \mathrm{C}[21]$. 
Synthesis of substituted pyrano-[2,3-d]-pyrimidines via one-pot three-component condensation of aromatic aldehydes, malononitrile and barbituric acid or 2-thiobarbituric acid using trace amounts of ionic liquid (choline chloride. $\mathrm{ZnCl}_{2}$ ) and triethanolamine $(0.1 \mathrm{Mol} \%)$ at $75^{\circ} \mathrm{C}$ with stirring and under ultrasound irradiation [22] is also reported in literature. Herein we successfully attempted a fast and simple protocol for the synthesis of 6-amino-1,4-dihydro-4-substituted-3-methylpyrano [2,3-c]pyrazole-5-carbonitrile by the one pot three component reaction of aromatic aldehyde, malononitrile and 3-methyl-1H-pyrazol-5(4H)one using triethanolamine as a catalyst [23].

\section{Result and Discussion}

To explore the synthetic application of triethanolamine, in the present work we report the catalytic facet of it for the synthesis of heterocyclic compounds bearing pyrazole skeleton. To optimize the reaction conditions, we choosed anisaldehyde as the prototype. Initially, $10 \mathrm{~mol} \%$ of triethanolamine was taken for solvent free reaction at room temperature. But the reaction afforded a low yield of the product after 2 hour stirring. Then we used $10 \mathrm{ml}$ of water for room temperature stirring [24]. After 2 hours stirring it gave $62 \%$ of yield. The yield of reaction gets drastically changed on increasing temperature. At $90^{\circ} \mathrm{C}$ we got $85 \%$ of yield of the product. When $20 \mathrm{~mol} \%$ of triethanolamine was used then we got $92 \%$ of yield at $90^{\circ} \mathrm{C}$ in $10 \mathrm{ml}$ water. Other solvents were also studied expecting better yield but other than ethanol and water we got poor yields (Table 1). Further increase of temperature and amount of triethanolamine did not improve yield significantly (Table 1). After optimizing the reaction conditions, differently substituted aldehydes with electron donating as well as electron withdrawing groups were reacted to examine the feasibility of this catalytic reaction (Scheme 1).

Table 1: Optimization of reaction conditions for the model reaction (Scheme)*

\begin{tabular}{|c|c|c|c|c|c|}
\hline Entry & Solvent & $\begin{array}{c}\text { Triethano- } \\
\text { lamine } \\
\text { (mol\%) }\end{array}$ & Temperature & $\begin{array}{c}\text { Time } \\
\text { (min.) }\end{array}$ & $\begin{array}{c}\text { Yield } \\
(\%) @ ~\end{array}$ \\
\hline 1 & -- & 10 & R.T. & 60 & 60 \\
\hline 2 & $\mathrm{CHCl}_{3}$ & 10 & Reflux & 60 & 41 \\
\hline 3 & $\mathrm{CH}_{2} \mathrm{Cl}_{2}$ & 10 & Reflux & 60 & 35 \\
\hline 4 & THF & 10 & Reflux & 60 & 45 \\
\hline 5 & Acetonitrile & 10 & Reflux & 60 & 55 \\
\hline 6 & Methanol & 10 & Reflux & 60 & 64 \\
\hline 7 & Ethanol & 10 & Reflux & 30 & 83 \\
\hline 8 & Water & 10 & R.T. & 60 & 62 \\
\hline 9 & Water & 10 & $900 \mathrm{C}$ & 20 & 85 \\
\hline 10 & Water & 20 & $900 \mathrm{C}$ & 15 & 92 \\
\hline 11 & Water & 20 & Reflux & 15 & 93 \\
\hline 12 & Water & 30 & $900 \mathrm{C}$ & 15 & 93 \\
\hline
\end{tabular}

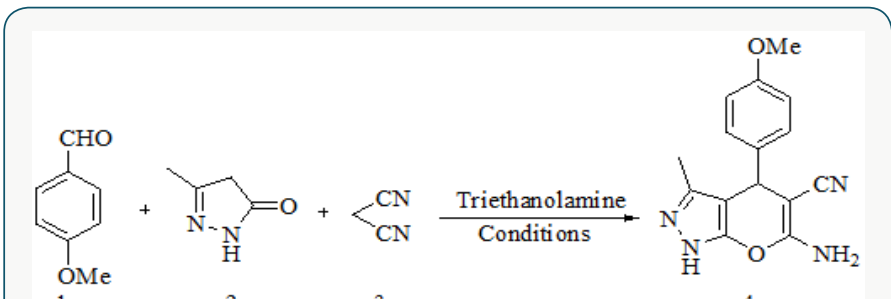

1a

3

$4 a$

Scheme 1: Model reaction for the synthesis of pyranopyrazoles.

Almost all aldehydes bearing various substituents such as - $\mathrm{Cl}, \mathrm{F}$, $-\mathrm{NO}_{2}$,-OMe etc afforded good yield of the corresponding products. All the synthesized compounds showed sharp peaks at $3410,3356 \mathrm{~cm}-$ $1\left(-\mathrm{NH}_{2}\right)$ and $2190 \mathrm{~cm}^{-1}(-\mathrm{CN})$ in IR spectra which supports for the formation of pyranopyrazole. The formed products being insoluble in water were easy to separate from the aqueous medium by simple filtration. The reason for catalytic activity of triethanolamine is it's solubility in aqueous medium and basic nature. Products are simply purified by re crystallization with ethanol. Thus the protocol described herein is efficient for the synthesis of pyrazopyrazoles which do not need purification by column chromatography.

Model reaction* for anisaldehyde (2mmol), malononitrile (2mmol) and 3-methyl-1H-pyrazol-5(4H)-one (2mmol) using the above cited conditions @Isolated yield.

\section{Experimental}

Melting points were recorded in open capillaries and were uncorrected. Progress of reaction was monitored by TLC $(30 \%$ of ethyl acetate: $\mathrm{n}$-hexane). IR spectra were taken by $\mathrm{KBr}$ disc on Shimadzu IR Affinity 1 spectrophometer. ${ }^{1} \mathrm{HNMR}$ spectra were recorded on a Varian $400 \mathrm{MHz}$ spectrophotometer in the specified solvents. Chemical shifts were expressed in $\delta$ ppm relative to TMS. Mass spectra were recorded on a Macro mass spectrometer (Waters) by electro spray method (ES).

General method for the synthesis of 6-amino-1, 4-dihydro-4-substituted-3-methylpyrano-[2,3-C]-pyrazole-5-carbonitrile

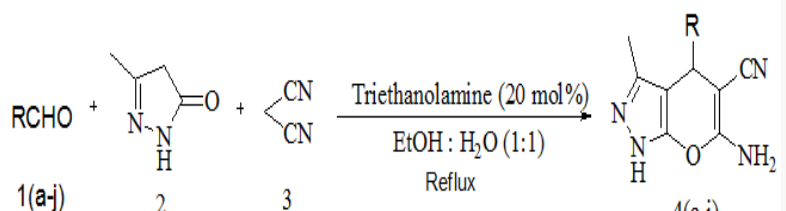

Scheme 2: General scheme for the one pot three component synthesis of pyranopyazoles using triethanolamine catalyst.

To a stirred mixture of aromatic aldehyde (2mmol), malononitrile $(2 \mathrm{mmol})$ and triethanolamine $(20 \mathrm{~mol} \%)$ in $10 \mathrm{ml}$ of water, 3-methyl-1H-pyrazol-5(4H)-one $(2 \mathrm{mmol})$ was added. The resulting mixture was stirred and heated at $90^{\circ} \mathrm{C}$ for appropriate 
reaction time (Table 2). After completion of reaction, the reaction mixture was cooled, filtered off the residue as the crude product which was further purified by re crystallization form ethanol (Scheme 2).

Table 2: Yield and reaction time of various pyranopyrazoles using triethanolamine.

\begin{tabular}{|c|c|c|c|c|c|c|}
\hline \multirow{2}{*}{ Entry } & \multirow{2}{*}{ Aldehyde } & \multirow{2}{*}{ Product } & \multirow{2}{*}{ Time (min.) } & \multirow{2}{*}{ Yield (\%) } & \multicolumn{2}{|c|}{ Melting point (OC) } \\
\hline & & & & & Obs. & Lit.(Ref.) \\
\hline 1 & 4-Methoxybenzaldehyde & $4 a$ & 15 & 92 & $210-211$ & $209-21122$ \\
\hline 2 & 4-Nitrobenzaldehyde & $4 b$ & 12 & 87 & $253-255$ & $254-25622$ \\
\hline 3 & 4-Hydroxybenzaldehyde & $4 c$ & 16 & 85 & $222-224$ & $221-22322$ \\
\hline 4 & 4-Bromobenzaldehyde & $4 d$ & 17 & 92 & $178-179$ & $179-18023$ \\
\hline 5 & Benzaldehyde & $4 \mathrm{e}$ & 15 & 90 & $245-246$ & $243-24422$ \\
\hline 6 & 4-Flurobenzaldehyde & $4 \mathrm{f}$ & 18 & 93 & $171-172$ & $171-17222$ \\
\hline 7 & 4-Chlorobenzaldehyde & $4 \mathrm{~g}$ & 15 & 91 & $230-232$ & $230-23222$ \\
\hline 8 & 2-Chlorobenzaldehyde & $4 \mathrm{~h}$ & 20 & 86 & $245-246$ & $244-24522$ \\
\hline 9 & Furfural & $4 \mathrm{i}$ & 20 & 81 & $241-242$ & $240-24222$ \\
\hline 10 & 4-(dimethylamino)benzaldehyde & $4 j$ & 17 & 82 & $234-235$ & 234-2358b \\
\hline
\end{tabular}

\section{Representative Spectral Data}

\section{6-Amino-1,4-dihydro-4-(4-methoxyphenyl)-3-methyl- pyrano[2,3-c]pyrazole-5-carbonitrile (4a)}

White solid, [1]H NMR (400 MHz, DMSO-d ${ }_{6}$ ): $\delta$ ppm 12.08 (s, $1 \mathrm{H}), 6.87-7.23$ (m, 4H), 6.81 (bs, 2H), 4.45 (s, 1H), 3.78 (s, 3H), 1.81 (s, 3H); IR (KBr) cm-1: 3425, 3128, 2928, 2200, 1597, 1153, 1203; ES-MS m/z: $283.2(\mathrm{M}+1)+$.

\section{6-Amino-2,4-dihydro-3-methyl-4-phenylpyrano[2,3-c] pyrazole- 5-carbonitrile (4e)}

White solid, M.P. 245-246 0C; 1H NMR (400 MHz, DMSO-d6) : $\delta$ ppm 12.10 (s, 1H), 7.10-7.40 (m, 5H), 6.85 (s, bs, 2H), 4.60 (s, 1H), 1.78 (s, 3H); IR (KBr) cm $\mathrm{cm}^{-1}: 3410,3356,3167,2990,1646,1596$, 1399, 1276, 870; ES-MS m/z: $253(\mathrm{M}+1)^{+}$.

6 - A m in o- 4 - ( 4 - chlorophenyl) - 3 - methyl - 2, 4 dihydropyrano[2,3-c]pyrazole-5-carbonitrile (4g)

Off-white solid, M.P. 230-2320C; ${ }^{1} \mathrm{H}$ NMR (400 MHz, DMSO-d ${ }_{6}$ ): $\delta$ ppm 12.15 (s, 1H), 7.10-7.40 (m, 4H), 6.95 (s, bs, 2H), 4.63 (s, 1H), 1.80 (s, 3H); IR (KBr) cm $\mathrm{cm}^{-1}: 3478,3035,2985,2193,1647,1596$, 1398, 1284, 870; ES-MS m/z: $287(\mathrm{M}+1)^{+}$.

\section{6-Amino-4-(4-N, N-dimethylaminophenyl)-3-methyl-2, 4-dihydropyrano[2, 3-c]pyrazole-5-carbonitrile (4j)}

Yellow solid, M.P. 234-235 0C; ${ }^{1} \mathrm{H}$ NMR (400 MHz, DMSO-d $): \delta$ ppm 12.10 (s, 1H), 6.70-7.15 (m, 4H); 6.55 (s, bs, 2H), 4.40 (s, 1H); 2.85 (s, 6H), 1.78 (s, 3H); IR (KBr) cm $\mathrm{cm}^{-1}: 3385,3172,2957,2189$, 1644, 1601, 1397, 1279, 868; ES-MS m/z: $296(M+1)^{+}$.

\section{Conclusion}

In summary, we have developed an efficient protocol for the synthesis of pyranopyrazoles by a simple method using a catalytic amount of triethanol amine. Herein; not only the yield of reaction is improved but also the reaction time is reduced. The workup of the reaction is very simple which make it easier to isolate the product.

\section{Acknowledgement}

The authors are thankful to The Principal, Vinayakrao Patil Mahavidyalaya, Vaijapur for providing laboratory facilities and The Director, SAIF, Chandigarh for NMR and Mass analysis.

\section{References}

1. Strecker A (1850) The artificial synthesis of lactic acid and a new homologue of glycine. Liebigs Ann Chem 75: 27-45.

2. Maleki B, Ashrafi SS (2014) Nano $\boldsymbol{\alpha}$ - $\mathrm{Al}_{2} \mathrm{O}_{3}$ supported ammonium dihydrogen phosphate $\left(\mathrm{NH}_{4} \mathrm{H}_{2} \mathrm{PO}_{4} / \mathrm{Al}_{2} \mathrm{O}_{3}\right)$ : preparation, characterization and its application as a novel and heterogeneous catalyst for the onepot synthesis of tetrahydrobenzo[b]pyran and pyrano-[2,3-c]pyrazole derivatives. RSC Adv 4(81) : 42873-42891.

3. Farahi M, Karami B, Sedighimehr I, Tanuraghaj HM (2014) An environmentally friendly synthesis of 1,4-dihydropyrano[2,3-c]pyrazole derivatives catalyzed by tungstate sulfuric acid. Chin Chem Lett 25(12): 1580-1582.

4. Azarifar D, Abbasi Y (2016) Sulfonic acid-functionalized magnetic $\mathrm{Fe}_{3}$ ${ }_{x} \mathrm{Ti}_{\mathrm{x}} \mathrm{O}_{4}$ nanoparticles: New recyclable heterogeneous catalyst for onepot synthesis of tetrahydrobenzo[b]pyrans and dihydropyrano [2, 3-c] pyrazole derivatives. Synth comm 46(9): 745-758.

5. Azarifar D, Khatami SM, Zolfigol MA, Nejat-Yami R (2014) Nanotitania sulfuric acid-promoted synthesis of tetrahydrobenzo[b]pyran and 1,4-dihydropyrano-[2,3-c]pyrazole derivatives under ultrasound irradiation. J Iran Chem Soc 11(4): 1223-1230.

6. Shinde PV, Gujar JB, Shingate BB, Shingare MS (2012) Silica in water: A potentially valuable reaction medium for the synthesis of pyrano-[2,3-c] pyrazoles. Bull Korean Chem Soc 33(4): 1345-1348.

7. Heravia MM, Ghodsa A, Derikvanda F, Bakhtiaria K, Bamoharramb FF (2010) $\mathrm{H}_{14}\left[\mathrm{NaP}_{5} \mathrm{~W}_{30} \mathrm{O}_{110}\right]$ catalyzed one-pot three-component synthesis of dihydropyrano[2,3-c]pyrazole and pyrano[2,3-d]pyrimidine derivatives. J Iran Chem Soc 7(3): 615-620.

8. Tekale SU, Kauthale SS, Jadhav KM, Pawar RP (2013) Nano-ZnO catalyzed green and efficient one-pot four-component synthesis of pyranopyrazoles. J Chem Article ID pp. 840954.

9. Samy AEA (2011) A simple and clean method for four-component synthesis of pyrano[2,3-c]pyrazole derivatives. Der Pharma Chemica 3(5): 81-86 
10. Wen LR, Lan MC, WK Yuan, M Li (2014) DABCO-mediated isocyanidebased multicomponent reaction: synthesis of highly substituted cyclopentenes. Org Biomol Chem 12(26): 4628-4632.

11. R Mohan, N Kalla, II Kim (2017) Tris(hydroxymethyl)aminomethaneas an efficient organobase catalyst for the synthesis of $\boldsymbol{\beta}$-phosphonomalonates. Tetrahedron Lett 58(5): 410-414.

12. Xiao B, Sun J, Wang J, Liu C, Cheng W (2013) Triethanolamine / KI: A multifunctional catalyst for $\mathrm{CO}_{2}$ activation and conversion with epoxides into cyclic carbonates. Synth Comm 43(22): 2985-2997.

13. Deping W, Daizhi K, Fuxing Z, Siping T, Wujiu J (2014) Triethanolamine as an inexpensive and efficient ligand for copper catalyzed hydroxylation of aryl halides in water. Eur J Org Chem (2): 315 - 318.

14. Mousavi SF, Davar F, Estarki MRL (2016) Controllable synthesis of ZnO nanoflowers by the modified sol-gel method. J Mat Sci: Mat Elect 27(12): 12985-12995.

15. Hasan MR, Binti SB, Hamid OAA, Basirun WJ (2015) Triethanolamine (TEA) aqueous solution as an Electrolyte promoter in $\mathrm{CO}_{2}$ photoelectroconversion under simulated solar irradiation assisted by $\mathrm{Cu}$-doped graphene-titania catalyst. Adv Mat Res 1109: 448-450

16. Hronec M, Veselý V (1975) Effect of triethanolamine on the activity of cobalt bromide catalysts at the oxidation of mesitylene. Collect Czech Chem Commun 40(7): 2165-2172.

17. Yang J, Wang D, Han H, Li C (2013) Roles of cocatalysts in photocatalysis and photoelectrocatalysis. Accounts Chem Res 46(8): 1900-1909.

18. Zhang P, Zhu Y, Yuan Z, Wu C, Tang H (2017) CuBr/PMDETA combined with triethanolamine as an economic and highly active catalyst for atom transfer radical polymerization. J Macromol Sci: Part A Pure \& Appl Chem 54 (10): 735-741.

19. Srinivas K, Dubey PK (2014) Triethanolamine: A resourceful, reusable, eco-friendly, reaction medium for phase transfer catalyst - free synthesis of 1-(arylsulfonyl) aryl/heterylmethanes. Chem Sci Trans 3(1): 375-381.

20. Srikrishna D, Tasqeeruddin S, Dubey PK (2014) Synthesis of 3-substituted coumarins: An efficient green approach using L-proline as catalyst in triethanolamine medium. Lett Org Chem 11(8): 556-563.

21. Khandebharad AU, Sarda SR, Soni MG, Joshi BJ, Runwal SM, et al. (2015) Triethanolamine as an efficient catalyst for one-pot synthesis of amino3-cyano-4H-pyran derivatives. J Med Chem \& Drug Dis Special Issue Analytical Chemistry Teachers and Researchers, Association National Convention / Seminar pp. 278-284.

22. Yadav DK, Quraishi MA (2014) Choline chloride. $\mathrm{ZnCl}_{2}$ : Green, effective and reusable ionic liquid for synthesis of 7-amino-2, 4-dioxo-5-phenyl-2, 3, 4, 5-tetrahydro-1H-pyrano [2, 3-d] pyrimidine-6-carbonitrile derivative. J Mater Environ Sci 5(4): 1075-1078.

23. Bhosle MR, Khillare LD, Dhumal ST, Mane RA (2016) A facile synthesis of 6-amino- $2 \mathrm{H}, 4 \mathrm{H}$-pyrano [2, 3-c] pyrazole-5-carbonitriles in deep eutectic solvent. Chin Chem Lett 27(3): 370-374.

24. Mecadon H, Rohman MR, Rajbangshi M, Myrboh B (2011) Fourcomponent Synthesis of 6-amino-4-alkyl/aryl-3-methyl-2,4dihydropyrano[2,3-c]pyrazole-5-carbonitriles in aqueous medium. Tetrahedron Lett 52: 2523-2525.

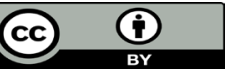

This work is licensed under Creative Commons Attribution 4.0 License

To Submit Your Article Click Here:

Submit Article

\section{AOICS}

DOI: $10.32474 /$ AOICS.2018.03.000155

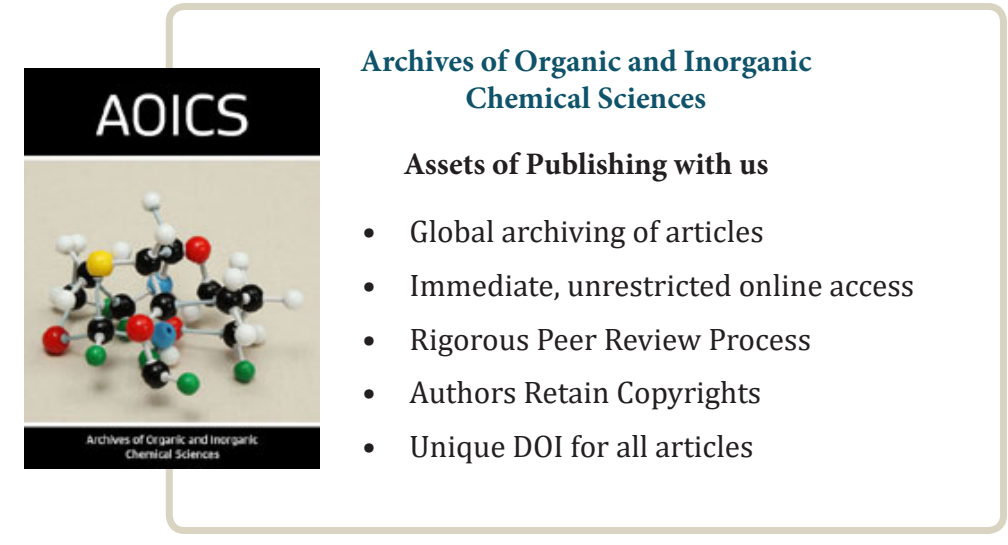

